\title{
Preoperative Bowel Preparation: Surgical Standard or Past?
}

\author{
Beat P. Müller-Stich Arash Choudhry Gregor Vetter Dalibor Antolovic \\ Arianeb Mehrabi Jörg Köninger Jürgen Weitz Markus W. Büchler \\ Carsten N. Gutt \\ Department of General, Abdominal and Transplant Surgery, University of Heidelberg, Heidelberg, Germany
}

\section{Key Words}

Preoperative bowel preparation • Bowel irrigation • Bowel

cleansing $\cdot$ Colorectal surgery

\begin{abstract}
Background: Preoperative bowel preparation is still routinely used prior to colorectal surgery. This concept is based on traditional and personal empiricism and usually not evidence based. The objective of the present review was to reassess this dogma against the background of the highest level of evidence published thus far. Methods: The Medline database was searched using the search terms 'preoperative', 'bowel' and 'preparation' limited to 'randomized controlled trials' and 'meta-analyses'. Ten randomised controlled trials and seven meta-analyses comparing orthograde bowel cleansing to no preoperative bowel preparation were considered for rates of anastomotic leakages, surgical infections and other types of complications, reoperations and mortality. Results: All the most recent meta-analyses showed a significant increase of anastomotic dehiscences in patients with preoperative orthograde bowel cleansing. Additionally, a trend towards higher rates of surgical infectious complications and re-operations was revealed. Mortality remained unchanged by preoperative orthograde bowel cleansing. Conclusion: Routine preoperative orthograde bowel cleansing is no longer justified prior to colorectal surgery in general due to increased risk of anastomotic leakages. Further investigations should focus on different types of bowel
\end{abstract}

preparation in situations where preoperative bowel preparation still may have a role such as total mesorectal resection with low anastomosis and protective ileostomy.

Copyright $\odot 2006$ S. Karger AG, Basel

\section{Introduction}

Bowel preparation by orthograde cleansing prior to colorectal surgery is still commonly recommended in several practical guidelines [1,2]. Accordingly, surveys in Europe [3] and the USA [4] showed a widespread application of preoperative bowel preparation with more than $99 \%$ surgeons using it in the USA. The main intention of such a practice is to reduce postoperative complications in addition to easing the intra-operative handling of the bowel. Especially the idea of decreasing postoperative complications such as anastomotic dehiscences, intra-abdominal septic complications and wound infections was nourished by the fact that these kinds of complications caused about half of the postoperative deaths in earlier patient series $[5,6]$. Since both the rate of anastomotic dehiscences and infections were attributed to an elevated intestinal contamination $[7,8]$, emptying the colon of its content seemed to be a logical step prior to interventions. Thus, preoperative bowel cleaning was established as a dogma in the early seventies [8-10]. However, there has always been little evidence to base the concept of preoperative bowel preparation on. Hughes [11] in 1972 was the

\section{KARGER}

Fax +4161306 1234

E-Mail karger@karger.ch

www.karger.com (c) 2006 S. Karger AG, Basel

$0253-4886 / 06 / 0236-0375 \$ 23.50 / 0$

Accessible online at:

www.karger.com/dsu
Carsten N. Gutt, MD

Department of General, Abdominal and Transplant Surgery

University of Heidelberg, Im Neuenheimer Feld 110, DE-69120 Heidelberg (Germany)

Tel. +496221 564828 , Fax +496221568641

E-Mail carsten.gutt@med.uni-heidelberg.de 
first to question the importance of preoperative bowel preparation in a randomized trial comparing preoperative enemas to no preoperative bowel preparation. Further indications of the limited utility of preoperative bowel preparation came from emergency colon surgery $[12,13]$ and from uncontrolled patient series $[14,15]$. Here, low rates of anastomotic leakage and postoperative infection were achieved not with preoperative bowel preparation, but rather with consistent antibiotic prophylaxis that proved to be effective in reducing infections after colon surgery [16].

Fortunately, today we have access to better evidence. Thus, we reviewed the literature with the highest level of evidence in order to reassess the dogma of preoperative bowel preparation and to clarify how essential it is, if at all.

\section{Methods}

In order to find the latest literature with the highest level of evidence to base the following statements on, a MEDLINE database search was performed with the search terms 'preoperative', 'bowel' and 'preparation' limited to 'randomized controlled trials' (RCTs) and 'meta-analyses'. Regarding RCTs, only trials published as original articles comparing orthograde bowel cleansing (OBC) to no preoperative bowel preparation were considered. All the reference lists in the selected articles were screened for additional trials using to the same criteria.

Nine relevant RCTs [17-25] (table 1) and 7 meta-analyses conducted by 5 different authors [26-32] (table 2) were retrieved. The meta-analyses included 3 RCTs published only as abstracts [3335]. Two of these, however, were published later as original articles $[17,19]$ and therefore also listed in table 1 . One additional RCT [36] not displayed in table 1 was included as a subgroup in the subsequent larger RCT by Fa-Si-Oen et al. [19]. The RCT by Fillmann et al. $[20,37]$ was published twice and thus, only counted once.

\section{Results}

\section{Anastomotic Dehiscences}

Because prevention of anastomotic dehiscence is one of the main goals of $\mathrm{OBC}$, all trials considered here focused on this issue. Apart from Burke et al. [18] all other RCTs showed fewer anastomotic dehiscences without OBC. Due to lack of power all but the trials of Tabusso et al. [24] and Brownson et al. [33] (1.5\% for no OBC versus $11.9 \%$ for OBC; only published as abstract and therefore not included in table 1) failed to reach statistical significance. All the meta-analyses suggested no OBC to be superior. However, only the 5 or 4 most recent, respectively ( 2 of them $[29,32]$ included the same 9 RCTs and were performed by the same author group), reached the level of significance.

A few RCTs stratified the risk of anastomotic dehiscence to the site of anastomosis. Most of the authors investigated study populations with all kinds of colorectal resections. Burke et al. [18] and Bucher et al. [17] included only left-sided colectomies; Fa-Si-Oen et al. [19] excluded ileocolonic and extraperitoneal colorectal anastomoses. Burke et al. [18] distinguished between patients with leftsided hemicolectomies ( $\mathrm{n}=54 ; 28$ without, 26 with OBC), anterior resections ( $\mathrm{n}=40 ; 23$ without, 17 with $\mathrm{OBC})$ and low anterior resections ( $\mathrm{n}=75 ; 36$ without, 39 with OBC). No patient with left-sided hemicolectomy and anterior resection suffered any anastomotic problems. After low anterior resection anastomotic dehiscence was present in 7 patients regardless of whether $\mathrm{OBC}$ had been done or not $(11.1 \%$ for no $\mathrm{OBC}$ versus $7.7 \%$ for $\mathrm{OBC}$; $\mathrm{p}=0.91)$. Miettinen et al. [21] reported 5 of 7 anastomotic dehiscences to be found in patients with low colonic anastomosis with a trend towards higher leakage rates in the group with $\mathrm{OBC}(14.3 \%$ for no OBC versus $33.3 \%$ for OBC; $\mathrm{p}=$ 0.28). In the series of Ram et al. [22] the 3 anastomotic dehiscences all occurred after anterior resection with a trend towards higher leakage rates in the group without OBC (10.0\% for no OBC versus 3.3\% for OBC; p value not stated). Fa-Si-Oen et al. [19] summarized that regarding the occurrence of anastomotic dehiscences between left and right hemicolectomies there was no significant difference. The only meta-analyses stratifying the risk of anastomotic dehiscence to the site of anastomosis are those by Guenaga et al. [28, 29]. In the updated version of 2005 [29], they calculated similar odds ratios (OR) regarding OBC for patients with low anterior resections $(1.45$; 95\% confidence interval (CI) $0.57-3.67)$ as for patients with other colonic resections (OR 1.8; CI 0.68-4.75).

Another interesting observation was made by Slim et al. [31] in their meta-analysis. They assessed trials in which polyethylene glycol (PEG) was used as an OBC solution, opposed to trials with other kinds of $\mathrm{OBC}$ solutions. After OBC with PEG the rate of anastomotic leakage was significantly higher than without OBC (OR 1.92; CI 1.03-3.60). Although the results still favored no OBC they were not significant for other preoperative bowel preparation regimes (OR 1.43; CI 0.59-3.45).

\section{Surgical Infectious Complications}

Another main issue of $\mathrm{OBC}$ is to limit surgical infectious complications after colorectal resections. Accordingly, this issue was also investigated in all the studies considered. Two main types of surgical infections - 
Table 1. Randomized controlled trials comparing no preoperative bowel preparation versus orthograde bowel cleansing regarding main issues such as anastomotic dehiscences and surgical infectious complications

\begin{tabular}{|c|c|c|c|c|c|}
\hline Author & $\begin{array}{l}\text { Number of } \\
\text { patients }\end{array}$ & Solution for $\mathrm{OBC}$ & $\begin{array}{l}\text { Anastomotic } \\
\text { dehiscences, } \%\end{array}$ & $\begin{array}{l}\text { Wound } \\
\text { infections, \% }\end{array}$ & $\begin{array}{l}\text { Intra-abdominal } \\
\text { infections, } \%\end{array}$ \\
\hline Burke et al. [18] & 87 vs. 82 & sodium picophosphate & 4.6 vs. 3.7 & 3.4 vs. 4.9 & not available \\
\hline Santos et al. [23] & 77 vs. 72 & mannitol & 5.2 vs. 9.7 & 11.7 vs. $23.6^{*}$ & not available \\
\hline Fillmann et al. [20] (Portuguese) & 30 vs. 30 & mannitol & 3.3 vs. 6.6 & 6.7 vs. 3.3 & not available \\
\hline Miettinen et al. [21] & 129 vs. 138 & PEG & 2.3 vs. 3.6 & 2.3 vs. 3.4 & 3.1 vs. 2.2 \\
\hline Tabusso et al. [24] (Spanish) & 23 vs. 24 & mannitol or PEG & 0 vs. $20.8^{*}$ & 0 vs. 8.3 & 0 vs. 13 \\
\hline Zmora et al. [25] & 193 vs. 187 & PEG & 2.1 vs. 3.7 & 5.7 vs. 6.4 & 1.0 vs. 1.1 \\
\hline Bucher et al. [17] & 75 vs. 78 & PEG & 1.3 vs. 6.4 & 5.3 vs. 12.8 & 2.6 vs. 2.6 \\
\hline Fa-Si-Oen et al. [19] & 125 vs. 125 & PEG & 4.8 vs. 5.6 & 5.6 vs. 7.2 & not available \\
\hline Ram et al. [22] & 165 vs. 164 & sodium phosphate & 0.6 vs. 1.2 & 6.1 vs. 9.8 & 0.6 vs. 0.6 \\
\hline
\end{tabular}

OBC = Orthograde bowel cleansing; PEG = polyethylene glycol.

* Statistically significant.

Table 2. Meta-analysis comparing no preoperative bowel preparation versus orthograde bowel cleansing regarding main issues such as anastomotic dehiscences and infectious complications

\begin{tabular}{|c|c|c|c|c|c|}
\hline Author & $\begin{array}{l}\text { Number } \\
\text { of trials }\end{array}$ & $\begin{array}{l}\text { Number of } \\
\text { patients }\end{array}$ & $\begin{array}{l}\text { Anastomotic dehiscences } \\
\text { (rates in \%) }\end{array}$ & $\begin{array}{l}\text { Wound infections } \\
\text { (rates in \%) }\end{array}$ & $\begin{array}{l}\text { Intra-abdominal infections } \\
\text { (rates in \%) }\end{array}$ \\
\hline \multirow[t]{2}{*}{ Platell et al. [30] } & \multirow[t]{2}{*}{3} & \multirow[t]{2}{*}{497} & rates: 8.1 vs. 10.8 & rates: 7.4 vs. $10.8^{*}$ & rates: not available \\
\hline & & & OR: not available & OR: not available & OR: not available \\
\hline \multirow[t]{2}{*}{ Bucher et al. [27] } & \multirow[t]{2}{*}{5} & \multirow[t]{2}{*}{1,144} & rates: 5.3 vs. 2.8 & rates: 5.7 vs. 6.4 & rates: 1.9 vs. 3.2 \\
\hline & & & OR: 1.76 ; CI 0.96-3.22 & OR: 1.37; CI 0.86-2.19 & OR: 1.48; CI 0.62-3.56 \\
\hline \multirow[t]{2}{*}{ Guenaga et al. [28] } & \multirow[t]{2}{*}{6} & \multirow[t]{2}{*}{1,159} & rates: 2.9 vs. 5.5 & rates: 5.7 vs. 7.4 & rates: 8.4 vs. 9.8 \\
\hline & & & OR: 1.94; CI 1.09-3.43* & OR: 1.33 ; CI $0.85-2.13$ & OR: $1.2 ;$ CI $0.70-2.04$ \\
\hline \multirow[t]{2}{*}{ Bucher et al. [26] } & \multirow[t]{2}{*}{7} & \multirow[t]{2}{*}{1,297} & rates: 2.8 vs. 5.6 & rates: 5.5 vs. 7.5 & rates: 2.0 vs. 3.7 \\
\hline & & & OR : $1.84 ;$ CI $1.08-3.22^{*}$ & OR: 1.38 ; CI $0.89-2.15$ & OR: $1.69 ;$ CI $0.76-3.75$ \\
\hline \multirow[t]{2}{*}{ Slim et al. [31] } & \multirow[t]{2}{*}{7} & \multirow[t]{2}{*}{1,454} & rates: 5.6 vs. 3.2 & rates: 5.7 vs. 7.4 & rates: not available \\
\hline & & & OR: 1.74 ; CI $1.05-2.90^{*}$ & OR: 1.33 ; CI $0.88-2.03$ & OR: not available \\
\hline Wille-Jörgensen et al. [32] & 9 & 1,592 & rates: 3.2 vs. 6.2 & rates: 5.4 vs. 7.4 & rates: 8.4 vs. $9.8^{\mathrm{a}}$ \\
\hline Guenaga et al. [29] & & & OR: 2.03; CI 1.28-3.26* & OR: 1.46; CI 0.97-2.18 & OR: 1.2 ; CI $0.70-2.04^{\mathrm{a}}$ \\
\hline
\end{tabular}

Rates in percent. OR = Odds ratio (values $>1.0$ favor no bowel preparation); $\mathrm{CI}=95 \%$ confidence interval.

* Statistically significant; ${ }^{\text {a }}$ only reported in the publication by Guenanga et al. [28].

wound infections and other intra-abdominal infections - were focused on.

Wound infection rates were higher in all the RCTs after OBC except for the one of Fillmann et al. [20] (table 1). However, the difference of 6.7 vs. $3.3 \%$ in this study was not significant. The trial of Santos et al. [23] was the only one with a significantly higher wound infection rate of $23.6 \%$ after OBC compared to $11.7 \%$ after no OBC. Remarkable was the overall high rate of wound infections of $17.4 \%$ in this study. All meta-analyses revealed a trend towards decreased wound infection rates with Platell et al. [30] being the only one who found a significant advantage for no $\mathrm{OBC}$ (table 2).

Intra-abdominal infections such as abscesses and peritonitis were investigated in only 5 RCTs $[17,21,22,24,25]$ (table 1) and 3 meta-analyses [26-28] (table 2). Three trials showed similar results regardless if $\mathrm{OBC}$ was performed or not [17, 22, 25]. Only in the RCT of Miettinen et al. [21] was a slight advantage revealed in favor of OBC, but this was not statistically significant. Tabusso et al. [24] found an insignificant increase of intra-abdominal infections after OBC, and Brownson et al. [33], whose results 
Table 3. Randomized controlled trials comparing no preoperative bowel preparation versus orthograde bowel cleansing regarding additional issues such as other than surgical infectious complications, re-operations, mortality and hospital stay

\begin{tabular}{|c|c|c|c|c|c|}
\hline Author & $\begin{array}{l}\text { Number of } \\
\text { patients }\end{array}$ & $\begin{array}{l}\text { Others than } \\
\text { surgical infectious } \\
\text { complications, \% }\end{array}$ & $\begin{array}{l}\text { Re-operations, } \\
\%\end{array}$ & $\begin{array}{l}\text { Mortality, } \\
\%\end{array}$ & $\begin{array}{l}\text { Hospital } \\
\text { stay, days }\end{array}$ \\
\hline Burke et al. [18] & 87 vs. 82 & 10.3 vs. 9.8 & not available & 0 vs. 2.4 & not available \\
\hline Santos et al. [23] & 77 vs. 72 & not available & 1.3 vs. 5.6 & 0 vs. 0 & not available \\
\hline Fillmann et al. [20] (Portuguese) & 30 vs. 30 & 16.6 vs. 10.0 & not available & not available & not available \\
\hline Miettinen et al. [21] & 129 vs. 138 & 5.0 vs. 8.0 & 2.3 vs. 5.1 & 0 vs. 0 & 8 vs. 8 \\
\hline Tabusso et al. [24] (Spanish) & 23 vs. 24 & not available & 0 vs. 0 & not available & 11 vs. $14^{*}$ \\
\hline Zmora et al. [25] & 193 vs. 187 & 28.0 vs. 28.3 & not available & 1.6 vs. 1.6 & 8 vs. 8 \\
\hline Bucher et al. [17] & 75 vs. 78 & 10.6 vs. $24.4^{*}$ & 2.7 vs. 9.0 & 0 vs. 0 & 10 vs. $15^{*}$ \\
\hline Fa-Si-Oen et al. [19] & 125 vs. 125 & not available & 8.8 vs. 10.8 & not available & 9 vs. 10 \\
\hline Ram et al. [22] & 165 vs. 164 & 27.3 vs. 33.5 & 1.2 vs. 1.2 & 1.2 vs. 1.2 & 8 vs. 8 \\
\hline
\end{tabular}

* Statistically significant.

were only published as an abstract, calculated even a significant disadvantage for $\mathrm{OBC}(2.2 \%$ for no $\mathrm{OBC}$ versus $9.3 \%$ for $\mathrm{OBC}$ ). Probably as a consequence of including also the results of Brownson et al. [33], all 3 meta-analyses dealing with intra-abdominal infections showed a slight but not significant advantage in favor of no OBC.

\section{Other Complications}

Other complications were analyzed in 6 of 9 RCTs (table 3). A significant difference in favor of no OBC was reported in the study of Bucher et al. [17]. Additionally, in the studies of Miettinen et al. [21] and Ram et al. [22] a trend towards an increase of such complications was seen after OBC. The only study indicating a decrease was the one by Fillmann et al. [20]. There were three metaanalyses, the second one of Bucher et al. [26] and both by Guenaga et al. [28, 29] focusing on these kinds of complications. Bucher et al. [26] calculated an OR of 1.15 (CI $0.79-1.7)$ in favor of no OBC. Guenaga et al. $[28,29]$ differentiated between infectious (OR 0.87; CI $0.41-1.87$ in both studies) and noninfectious $(1.19 ; 0.61-2.32$ in the earlier and $1.09 ; 0.75-1.58$ in the later study) extra-abdominal complications (an OR $>1$ favouring no OBC). Four authors looked at the duration of postoperative bowel restoration and ileus, respectively, as a particular postoperative problem. Miettinen et al. [21] and Zmora et al. [25] reported equal rates of postoperative ileus regardless of whether $\mathrm{OBC}$ was done (1.6\% for no OBC versus $0.7 \%$ for $\mathrm{OBC}$ and 3.1 vs. $3.7 \%$, respectively). Fa-SiOen et al. [19] and Bucher et al. [17] recorded the postoperative time until the first bowel movements. Fa-Si-Oen et al. [19] found the same duration in both groups. Bucher et al. [17], however, had a significantly prolonged bowel restoration after $\mathrm{OBC}$ of 3.9 vs. 2.5 days.

\section{Re-Operations}

Six RCTs investigated the rate of re-operations (table 3). When OBC was applied re-operation rate was either higher or similar but not lower in any trial. A distinct trend towards increased re-operation rates was detected in the trials of Santos et al. [23], Miettinen et al. [21] and Bucher et al. [17] but none of the findings was statistically significant. Meta-analyses dealing with re-operation rates were those of Bucher et al. $[26,27]$ and Guenaga et al. [28, 29]. Bucher et al. [17] calculated insignificant higher re-operation rates in both of his meta-analyses (OR 1.54; CI 0.64-3.72 in the earlier and 1.72; 0.81-3.65 in the later study), similar to the results of Guenaga et al. $[28,29](1.40 ; 0.56-3.49$ and $1.8 ; 0.81-3.98$, respectively). Four authors itemized the reasons for re-operations [17, 21-23]. Twenty of 27 re-operations in total (74.1\%) were related to anastomotic dehiscences and surgical infectious complications.

\section{Mortality}

Mortality was a rare event and equally occurring in both the no $\mathrm{OBC}$ and $\mathrm{OBC}$ group (table 3). Only in the study of Burke et al. [18] there was a slight difference with no mortality in the no-OBC group with 36 patients, compared to 2 deaths in the OBC group with 39 patients. Four of 12 deaths (33.3\%) reported in 6 studies [18, 19, 21-23, 25 ] were related to surgical infectious complications, the 
remaining ones to cardiopulmonary problems. Five of 7 meta-analyses went for the calculation of an OR for mortality although there was only a maximum of 8 deaths in the most recent study by Guenaga et al. [29]. The respective ORs were 1.42 (CI 0.37-5.45) by Bucher et al. [26], $7.95(0.49-128.34)$ in the earlier study of Guenaga et al. [28], $1.56(0.45-5.45)$ by Slim et al. [31] and $1.72(0.43-$ $6.95)$ in the two most recent studies by the same author group of Guenaga, Wille-Jörgensen et al. [29, 32] (an OR $>1$ favoring no $\mathrm{OBC}$ ).

\section{Conclusion}

Regarding anastomotic dehiscence and surgical infectious complications, current clinical research offers no evidence to support the claim that OBC should be performed prior to colorectal surgery. In a critical retrospective view this idea essentially seems to have been promoted by the belief that the absence of stool in the intestine must be advantageous. At no point did the current literature prove that preoperative $\mathrm{OBC}$ could reduce postoperative complications. On the contrary, all the most recent meta-analyses (table 2) revealed a significant increase of risk for anastomotic dehiscences after OBC. Indeed, this observation is in accordance with some experimental studies indicating histological damage and impairment of anastomotic healing after bowel preparation prior to colonic resection [38-40]. But even the rate of surgical infectious complications such as wound infections, abscesses and peritonitis could not be lowered by preoperative $\mathrm{OBC}$ according to the highest level of evidence in the literature. This also is not surprising when one takes into account that preoperative bowel preparation does not reduce bacterial contamination in either the abdominal cavity or the subcutis [36]. Furthermore, potential side-effects such as electrolytic and hydration disorders, patient discomfort, medical and nursing labor and - as a consequence - costs have to be taken into consideration. Omitting OBC may, for example, decrease hospital stay which was indicated by the RCTs of Tabusso et al. [24] and Bucher et al. [17]. Hospital stay may not only be reduced due to the shortening of the preoperative phase but may also be attributed to a decreased re-operation rate and reduction of postoperative ileus. Thus, our review revealed a trend towards higher re-operation rates. Concerning postoperative ileus, which was intended to be shortened by preoperative bowel preparation, our review showed no advantage for OBC. Bucher et al. [17] as 1 of 4 authors $[17,19,21,25]$ focusing on this issue reported in his RCT even a prolongation of time until the first bowel movements.

Probably, there may be particular situations in which OBC could be useful. For example, rectum resection with total mesorectal excision and low anastomosis may benefit from OBC. In these operations, a protective stoma is commonly recommended because, in spite of an excellent technique, the rate of anastomotic leakages remains a problem in this region [41]. In this regard, a cleaned bowel might be an advantage for the further course when anastomotic leakage occurs. Otherwise, no protective stoma would be needed. Furthermore, the question whether anastomotic dehiscence can be prevented at least in the low extraperitoneal region is unanswered. Although, all authors $[18,19,21,22,28,29]$ stratifying the risk of anastomotic dehiscence to the site of anastomosis failed to find an advantage for OBC after low colorectal anastomosis. Another issue might be the type of solution used for OBC. If there remains a reason for performing $\mathrm{OBC}$ then it would be of use to know the best tolerated and most effective agent for it. An observation in this regard was made by Slim et al. [31] in their meta-analysis, as they had recognized that anastomotic dehiscences were only increased significantly after OBC with PEG but not with other $\mathrm{OBC}$ solutions.

In conclusion, $\mathrm{OBC}$ as a general recommendation before colorectal resections should be omitted. There might be some exceptions with a benefit for OBC worthy of future investigations.

\section{References}

1 The Association of Coloproctology of Great Britain and Ireland: Guidelines for the Management of Colorectal Cancer. London, Association of Coloproctology of Great Britain and Ireland, 2001.

Preoperative Bowel Preparation
-2 Otchy D, Hyman NH, Simmang C, Anthony T, Buie WD, Cataldo P, Church J, Cohen J, Dentsman F, Ellis CN, Kilkenny JW 3rd, Ko C, Moore R, Orsay C, Place R, Rafferty J, Rakinic J, Savoca P, Tjandra J, Whiteford M: Practice parameters for colon cancer. Dis Colon Rectum 2004;47:1269-1284.

\footnotetext{
-3 Kehlet H, Williamson R, Buchler MW, Beart RW: A survey of perceptions and attitudes among European surgeons towards the clinical impact and management of postoperative ileus. Colorectal Dis 2005;7:245-250.
} 
4 Zmora O, Wexner SD, Hajjar L, Park T, Efron JE, Nogueras JJ, Weiss EG: Trends in preparation for colorectal surgery: survey of the members of the American Society of Colon and Rectal Surgeons. Am Surg 2003;69:150154.

5 Glenn F, McSherry CK: Carcinoma of the distal large bowel: 32-year review of 1,026 cases. Ann Surg 1966;163:838-849.

-6 Fielding LP, Stewart-Brown S, Blesovsky L, Kearney G: Anastomotic integrity after operations for large-bowel cancer: a multicentre study. Br Med J 1980;281:411-414.

$\checkmark 7$ Everett MT, Brogan TD, Nettleton J: The place of antibiotics in colonic surgery: a clinical study. Br J Surg 1969;56:679-684.

-8 Barker K, Graham NG, Mason MC, De Dombal FT, Goligher JC: The relative significance of preoperative oral antibiotics, mechanical bowel preparation, and preoperative peritoneal contamination in the avoidance of sepsis after radical surgery for ulcerative colitis and Crohn's disease of the large bowel. Br Surg 1971;58:270-273.

$\checkmark 9$ Nichols RL, Condon RE: Preoperative preparation of the colon. Surg Gynecol Obstet 1971;132:323-337.

-10 Rosenberg IL, Graham NG, De Dombal FT, Goligher JC: Preparation of the intestine in patients undergoing major large-bowel surgery, mainly for neoplasms of the colon and rectum. Br J Surg 1971;58:266-269.

$>11$ Hughes ES: Asepsis in large-bowel surgery. Ann R Coll Surg Engl 1972;51:347-356.

-12 Burch JM, Martin RR, Richardson RJ, Muldowny DS, Mattox KL, Jordan GL Jr: Evolution of the treatment of the injured colon in the 1980s. Arch Surg 1991;126:979-983.

13 Memon MA, Devine J, Freeney J, From SG: Is mechanical bowel preparation really necessary for elective left sided colon and rectal surgery? Int J Colorectal Dis 1997;12:298302 .

- 14 Irving AD, Scrimgeour D: Mechanical bowel preparation for colonic resection and anastomosis. Br J Surg 1987;74:580-581.

15 Duthie GS, Foster ME, Price-Thomas JM, Leaper DJ: Bowel preparation or not for elective colorectal surgery. J R Coll Surg Edinb 1990;35:169-171.

-16 Baum ML, Anish DS, Chalmers TC, Sacks HS, Smith H Jr, Fagerstrom RM: A survey of clinical trials of antibiotic prophylaxis in colon surgery: evidence against further use of no-treatment controls. N Engl J Med 1981; 305:795-799.

-17 Bucher P, Gervaz P, Soravia C, Mermillod B, Erne M, Morel P: Randomized clinical trial of mechanical bowel preparation versus no preparation before electiveleft-sided colorectal surgery. Br J Surg 2005;92:409-414.
18 Burke P, Mealy K, Gillen P, Joyce W, Traynor $\mathrm{O}$, Hyland J: Requirement for bowel preparation in colorectal surgery. Br J Surg 1994;81: 907-910.

19 Fa-Si-Oen P, Roumen R, Buitenweg J, van Geldere D, Putter H, Verwaest C, Verhoef L, de Waard JW, Swank D, D'Hoore A, Croiset VU: Mechanical bowel preparation or not? Outcome of a multicenter, randomized trial in elective open colon surgery. Dis Colon Rectum 2005;48:1509-1516.

20 Fillman LS, Perondi F, Fillmann HS, Fillmann EEP: The elective resection for colorectal cancer without mechanical bowel preparation. Rev Brasil Coloproctol 2001;21: 246-248.

21 Miettinen RP, Laitinen ST, Makela JT, Paakkonen ME: Bowel preparation with oral polyethylene glycol electrolyte solution vs. no preparation in elective open colorectal surgery: prospective, randomized study. Dis Colon Rectum 2000;43:669-675.

22 Ram E, Sherman Y, Weil R, Vishne T, Kravarusic D, Dreznik Z: Is mechanical bowel preparation mandatory for elective colon surgery? A prospective randomized study. Arch Surg 2005;140:285-288.

23 Santos JC, Jr., Batista J, Sirimarco MT, Guimaraes AS, Levy CE: Prospective randomized trial of mechanical bowel preparation in patients undergoing elective colorectal surgery. Br J Surg 1994;81:1673-1676.

24 Tabusso FY, Zapata CJ, Espinoza BF, Meza P, Fugueroa RE: Mechanical preparation in elective colorectal surgery, a useful practice or need. Rev Gastroenterol Peru 2002;22: 152-158.

25 Zmora O, Mahajna A, Bar-Zakai B, Rosin D, Hershko D, Shabtai M, Krausz MM, Ayalon A: Colon and rectal surgery without mechanical bowel preparation: a randomized prospective trial. Ann Surg 2003;237:363367.

-26 Bucher P, Mermillod B, Gervaz P, Morel P: Mechanical bowel preparation for elective colorectal surgery: a meta-analysis. Arch Surg 2004;139:1359-1364.

27 Bucher P, Mermillod B, Morel P, Soravia C: Does mechanical bowel preparation have a role in preventing postoperative complications in elective colorectal surgery? Swiss Med Wkly 2004;134:69-74.

28 Guenaga KF, Matos D, Castro AA, Atallah AN, Wille-Jorgensen P: Mechanical bowel preparation for elective colorectal surgery. Cochrane Database Syst Rev 2003; CD001544.

29 Guenaga KF, Matos D, Castro AA, Atallah AN, Wille-Jorgensen P: Mechanical bowel preparation for elective colorectal surgery. Cochrane Database Syst Rev 2005; CD001544.
30 Platell C, Hall J: What is the role of mechanical bowel preparation in patients undergoing colorectal surgery? Dis Colon Rectum 1998;41:875-882.

31 Slim K, Vicaut E, Panis Y, Chipponi J: Metaanalysis of randomized clinical trials of colorectal surgery with or without mechanical bowel preparation. Br J Surg 2004;91: 1125-1130.

32 Wille-Jorgensen P, Guenaga KF, Matos D, Castro AA: Preoperative mechanical bowel cleansing or not? An updated meta-analysis. Colorectal Dis 2005;7:304-310.

33 Brownson P, Jenkins SA, Nott D, Ellenbogen S: Mechanical bowel preparation before colorectal surgery: results of a prospective randomized trial. Br J Surg 1992;79:461462.

34 Bucher P, Soravia C, Gervaz P, et al: Post-operative complications after elective colorectal surgery in regards of bowel preparation: results of a prospective randomized trial. Gastroenterology 2003;124:817.

35 Fa-Si-Oen P, Buitenweg JA, van Geldere D, de Waard JW, Swank X, Putter H, et al: The effect of preoperative bowel preparation with polyethylene glycol on surgical outcome in elective open colorectal surgery - a randomized multicentre trial. Fourth Belgian Surgical Week, Ostende, 2003.

36 Fa-Si-Oen PR, Verwaest C, Buitenweg J, Putter H, de Waard JW, van de Velde CJ, Roumen RM: Effect of mechanical bowel preparation with polyethyleneglycol on bacterial contamination and wound infection in patients undergoing elective open colon surgery. Clin Microbiol Infect 2005;11:158160.

37 Fillmann EEP, Fillmann HS, Fillmann LS: Elective colorectal surgery without mechanical prepare. Rev Bras Colo-Proct 1995;15: $70-71$.

38 Bingol-Kologlu M, Senocak ME, Talim B, Kale G, Ocal T, Buyukpamukcu N: A comparative histopathologic evaluation of the effects of three different solutions used for whole bowel irrigation: an experimental study. J Pediatr Surg 2000;35:564-568.

39 Coskun A, Uzunkoy A, Duzgun SA, Bozer M, Ozardali I, Vural H: Experimental sodium phosphate and polyethylene glycol induce colonic tissue damage and oxidative stress. Br J Surg 2001;88:85-89.

40 Okada M, Bothin C, Kanazawa K, Midtvedt $\mathrm{T}$ : Experimental study of the influence of intestinal flora on the healing of intestinal anastomoses. Br J Surg 1999;86:961-965.

41 Kapiteijn E, Putter H, van de Velde CJ: Impact of the introduction and training of total mesorectal excision on recurrence and survival in rectal cancer in The Netherlands. $\mathrm{Br}$ J Surg 2002;89:1142-1149. 